\title{
Microvascular Perfusion Is Impaired in a Rat Model of Normotensive Sepsis
}

\author{
Calvin Lam, Karel Tyml, Claudio Martin, and William Sibbald \\ The A. C. Burton Vascular Biology Laboratory, Victoria Hospital Research Institute and the Department of Medical Biophysics and the \\ Program in Critical Care Medicine, University of Western Ontario, London, Canada N6A 4G5
}

\begin{abstract}
We hypothesized that normotensive sepsis affects the ability of the microcirculation to appropriately regulate microregional red blood cell ( $R B C$ ) flux. An extensor digitorum longus muscle preparation for intravital study was used to compare the distribution of $\mathrm{RBC}$ flux and the functional hyperemic response in SHAM rats and rats made septic by cecal ligation and perforation (CLP). Using intravital microscopy, we found that sepsis was associated with a $36 \%$ reduction in perfused capillary density (from $35.3 \pm 1.5$ to $22.5 \pm 1.0$ capillaries $/ \mathrm{mm}$ of test line) and a $265 \%$ increase in stopped-flow capillaries (from $0.9 \pm 0.2$ to $3.3 \pm 0.4$ capillaries/mm); the spatial distribution of perfused capillaries was also $72 \%$ more heterogeneous. Mean intercapillary distance (ICD) increased $30 \%$ (from $25.7 \pm 0.8$ to $33.5 \pm 1.6$ $\mu \mathrm{m})$, and the proportion of capillary pairs with intercapillary distances $>33.8 \mu \mathrm{m}$ (the 75th percentile of ICD $_{\mathrm{SHAM}}$ ) was greater with sepsis. Mean capillary $\mathbf{R B C}$ velocity increased 17\% in CLP rats (391 vs $333 \mu \mathrm{m} / \mathrm{s}$ ). Laser Doppler flowmetry was used to assess the functional hyperemic response of the extensor digitorum longus muscle before and after a period of maximal twitch contraction designed to increase oxygen demand. RBC flux was $36 \%$ lower in the CLP rats at rest. After contraction, $R B C$ flux increased in both SHAM and CLP rats; however, the relative increase was less in the CLP group. We concluded that sepsis affects the ability of the skeletal muscle microcirculation to appropriately distribute $R B C$ flux and to respond to increases in oxygen need. (J. Clin. Invest. 1994. 94:2077-2083.) Key words: septicemia - microcirculation - capillaries - blood circulation - muscles, blood supply
\end{abstract}

\section{Introduction}

Although an increase in systemic and regional oxygen delivery $\left(\mathrm{QO}_{2}\right)$ usually accompanies the hyperdynamic circulatory response seen in early sepsis, there remains evidence that sepsis is associated with a defect in tissue oxygen utilization (1-3). Sepsis increases tissue oxygen consumption $\left(\mathrm{VO}_{2}\right)$ in the whole body and in individual organs $(2,4)$, yet a state of "pathologic" supply dependency (a condition where oxygen consumption is limited despite normal or high levels of oxygen delivery) has

Address correspondence to Calvin Lam, M.D., FRCPC, Room 315 Grey Nuns Building, Holy Cross Hospital, 2210-2 Street SW, Calgary, Alberta, Canada T2S 1S6. 1994.

Received for publication 26 May 1993 and in revised form 28 July

J. Clin. Invest.

(c) The American Society for Clinical Investigation, Inc.

$0021-9738 / 94 / 11 / 2077 / 07 \quad \$ 2.00$

Volume 94, November 1994, 2077-2083 been shown to exist in this syndrome $(2,5)$. Furthermore, the oxygen extraction ratio $\left(\mathrm{O}_{2} \mathrm{ER}\right)$ is typically reduced while the mixed venous oxygen saturation $\left(\mathrm{S}_{\mathrm{v}} \mathrm{O}_{2}\right)$ is increased in the presence of an elevated arterial lactate $(3,6)$. These abnormalities suggest the presence of an inefficiency in peripheral oxygen use that could be explained by a sepsis-induced maldistribution of oxygen delivery at the microregional level. This latter process could lead to microregional areas of hypoxia and may explain the presence of widespread microscopic areas of patchy tissue injury reported in animal models of sepsis $(7,8)$. The progression of this injury pattern may contribute to the pathogenesis of multiple organ dysfunction syndrome (MODS ), ${ }^{1}$ a complication of sepsis (9).

Maldistribution of tissue oxygen delivery may result from changes in the normal pattern of microvascular perfusion. Previous studies, which have used in vivo microscopy techniques to study changes in the microcirculation with sepsis, have examined the arterioles and venules rather than the capillaries which are the primary exchange vessels for waste products and metabolites, including oxygen. For example, Cryer and co-workers $(10,11)$ have shown that during the hyperdynamic state after an acute infusion of either live Escherichia coli bacteria or endotoxin, first and second order arterioles constrict, while third and fourth order arterioles dilate and venular diameters remain unchanged. Baker and co-workers $(12,13)$ reported that infusing endotoxin restricts red blood cell ( RBC) flow by causing arteriolar constriction and increased $\mathrm{RBC}$ transit time relative to plasma transit time. It has also been demonstrated in sepsis that the arterioles have impaired reactivity (14-17) and that endogenous vasodilators are necessary for the maintenance of arteriolar RBC flux (18). What net effects these changes have on RBC flux through the capillaries and, therefore, on the distribution of oxygen in the tissues is unclear.

We hypothesized that sepsis disrupts the ability of the capillary network to appropriately control RBC flux within the parenchyma of organs remote from the site of infection. The objective of this study was to use an in vivo skeletal muscle preparation to describe the changes induced in its capillary network by cecal ligation and perforation (CLP) in a rat model of sepsis. We used intravital videomicroscopy to observe the distribution of (a) perfused capillaries, and $(b)$ red blood cell velocities $\left(V_{\mathrm{RBC}}\right)$. We also used laser Doppler flowmetry to $(a)$ document the red blood cell flux ( $\left.Q_{\mathrm{RBC}}\right)$, and $(b)$ to measure the functional hyperemic response to experimentally induced muscle twitching. This study is unique for two reasons. First, it used a

1. Abbreviations used in this paper: ANCOVA, analysis of covariance $\mathrm{CD}$, capillary density; $\mathrm{CI}$, cardiac index; CLP, cecal ligation and perforation; CO, cardiac output; CV, coefficient of variation; EDL, extensor digitorum longus; ICD, intercapillary distance; LACT, arterial serum lactate; LDF, laser Doppler flow; MAP, mean arterial pressure; MODS, multiple organ dysfunction syndrome; $\mathrm{p}_{\mathrm{a}} \mathrm{O}_{2}$, arterial $\mathrm{O}_{2}$ tension; $Q_{\mathrm{RBC}}$, red blood cell flux; RBC, red blood cell; TEMP, core body temperature; $V_{\mathrm{RBC}}$, red blood cell velocity. 
subacute model of sepsis that closely reproduces the clinical situation, and, second, it directly examined the effects of sepsis on the distribution of red blood cells in the capillaries.

\section{Methods}

Animal preparation. After a 1-wk period of acclimatization to the laboratory, male Sprague-Dawley rats $(350-400 \mathrm{~g})$ underwent preparatory surgery under general anesthesia with isoflurance (1-2\%) and oxygen. A venous catheter (PE-50; Clay Adams, Parsippany, NJ) was advanced into the superior vena cava through the right external jugular vein. A specially constructed combination arterial catheter (PE-50; Clay Adams) and thermocouple microprobe (IT-21; Physitemp, Clifton, NJ) was advanced to the ascending aorta by way of the right carotid artery. All catheters were tunneled subcutaneously to the interscapular region and attached to a swivel harness (Harvard Instruments, St. Laurent, Quebec, Canada). The rats were then randomized to $(a)$ the SHAM group where a sham laparotomy was performed, or $(b)$ the CLP group where an intraperitoneal focus of infection was induced by cecal ligation and perforation (19). Briefly, this latter procedure entailed a midline laparotomy incision followed by the identification, devascularization, and ligation of the cecum just distal to the ileocecal valve. The cecum was then punctured twice with an 18-gauge needle, the bowel returned to the peritoneal cavity, and the incision closed with 2-0 silk. All rats were allowed to recover from anesthesia and had free access to rat chow and water. Rats in both groups received an intravenous bolus of $0.9 \%$ saline $(2 \mathrm{ml} / 100 \mathrm{~g})$ followed by fluid resuscitation with $0.9 \%$ saline $(1 \mathrm{ml} / 100 \mathrm{~g}$ per $\mathrm{h})$ and analgesia with fentanyl $(1 \mu \mathrm{g} / 100 \mathrm{~g}$ per $\mathrm{h})$. Arterial catheter patency was maintained by a continuous infusion at $0.5 \mathrm{ml} / \mathrm{h}$ of $0.9 \%$ saline containing heparin $(1 \mathrm{U} / \mathrm{ml})$.

Experimental protocol. $24 \mathrm{~h}$ after preparatory surgery, a baseline study was performed with the rats awake. Core body temperature (TEMP) was measured with the thermocouple microprobe. Mean arterial pressure (MAP) and central venous pressure was measured using disposable transducers (Uniflow; Baxter Healthcare Corp., Toronto, Ontario, Canada) and a display monitor (78353B; Hewlett-Packard Co., Mississauga, Ontario, Canada). The heart rate was determined from a recording of the arterial pressure trace. Cardiac output (CO) was measured by thermodilution using $200 \mu \mathrm{l}$ of room temperature $0.9 \%$ saline injected through the venous catheter and a cardiac output computer (Cardiotherm 500 AC-R; Columbus Instruments, Columbus, $\mathrm{OH}$ ); the $\mathrm{CO}$ was determined in triplicate and then averaged. Blood samples were withdrawn for measurement of hemoglobin $(\mathrm{Hb})$, white blood cell count and differential, arterial serum lactate (LACT), arterial pH, arterial $\mathrm{CO}_{2}$ tension $\left(\mathrm{p}_{\mathrm{a}} \mathrm{CO}_{2}\right)$, arterial $\mathrm{O}_{2}$ tension $\left(\mathrm{p}_{\mathrm{a}} \mathrm{O}_{2}\right)$, and arterial $\mathrm{O}_{2}$ saturation $\left(\mathrm{S}_{\mathrm{a}} \mathrm{O}_{2}\right)$.

The rat was then reanesthetized with isoflurane (SHAM 1.5\%, CLP $0.9 \%$ [20]), oxygen (percentage varied to maintain $\mathrm{p}_{\mathrm{a}} \mathrm{O}_{2} 90-100$ $\mathrm{mmHg}$ ), and nitrogen by mask. The rat was transferred to the stage of an intravital microscope (ELR; Leitz, Scarborough, Ontario, Canada) with a heating pad (K20C; American Medical System, Cincinnati, $\mathrm{OH}$ ) maintained at $37^{\circ} \mathrm{C}$. The rat was then placed on its left side, and the right hind limb was held up by a clamp support attached to the microscope stage. The extensor digitorum longus (EDL) muscle was then carefully surgically exposed and prepared for intravital study as described previously by our group (21). The preparation was allowed to stabilize for $30 \mathrm{~min}$ before the microcirculation was studied.

Intravital videomicroscopy followed by laser Doppler flowmetry studies were then performed. Repeat measurements of TEMP, heart rate, MAP, central venous pressure, $\mathrm{CO}, \mathrm{Hb}$, white blood cell, LACT, $\mathrm{pH}$, $\mathrm{p}_{\mathrm{a}} \mathrm{CO}_{2}, \mathrm{p}_{\mathrm{a}} \mathrm{O}_{2}$, and $\mathrm{S}_{\mathrm{a}} \mathrm{O}_{2}$ were taken after the EDL preparation, during each of the intravital videomicroscopy and laser Doppler flowmetry studies, and at the conclusion of the experiment to ensure that the rats remained stable throughout the period of anesthesia.

The animal protocol was reviewed and approved by the University of Western Ontario Committee on Animal Care.

Intravital videomicroscopy. The muscle surface was epi-illuminated by two flexible fiber optic light guides connected to a halogen light source (KL 1500; Schott, Wiesbaden, Germany). Each light guide was equipped with a focusing lens and green filter, and each was positioned by means of a micromanipulator. The EDL microcirculation was viewed through a long working distance objective ( $10 \times$ Leitz), a magnification changer (Leitz), and a closed circuit television system (Pacecon video camera; Dage-MTI, Scarborough, Ontario, Canada; TM-1400SU video monitor and BR-S601MU S-VHS video recorder; JVC, Scarborough, Ontario, Canada). The final magnification was 331. A time code generator/reader (T5010; Telcom Research, Burlington, Ontario, Canada) was used to imprint individual video frames with an identifying code for later frame-by-frame analysis. 2-min recordings of six randomly chosen videofields were then taken from the EDL muscle of each rat. The camera was rotated so that the capillaries were oriented horizontally across the video monitor screen for ease of subsequent analysis. In addition, if an arteriole was present, it was centered in the video field to maximize the number of different capillaries seen. Upon later playback, each video field was analyzed for capillary density, intercapillary distance, and red blood cell velocity.

Capillary density (CD) was determined by counting the number of capillaries crossing a 1-mm test line drawn perpendicular to the direction of the muscle fibers. For each video field, counts were obtained along three lines and then averaged. The $C D$ for each of the six video fields was then averaged to get a mean $C D$ for the EDL muscle. The coefficient of variation ( $\mathrm{CV}=$ standard deviation divided by the mean) of $\mathrm{CD}$ for the EDL was also calculated; this variable gives a measure of the spatial heterogeneity or uniformity of distribution of the capillaries. The CD was determined for capillaries with: $(a)$ stopped flow $\left(\mathrm{CD}_{\text {srop }}\right)$ in which there was no RBC transit within the capillary throughout the 2-min observation period; $(b)$ intermittent flow $\left(\mathrm{CD}_{\mathrm{INTER}}\right)$ in which $\mathrm{RBC}$ transit was transiently absent within the capillary for at least $30 \mathrm{~s}$ during the 2-min observation period; $(c)$ continuous flow $\left(\mathrm{CD}_{\mathrm{CoNT}}\right)$ in which there was continuous $R B C$ transit within the capillary throughout the 2-min observation period; $(d)$ perfused $\left(\mathrm{CD}_{\mathrm{PER}}\right)$ which was the sum of $\mathrm{CD}_{\mathrm{INTER}}$ and $\mathrm{CD}_{\text {CONT }}$; and $(e)$ total $\left(\mathrm{CD}_{\mathrm{TOTAL}}\right)$ which was the sum of $\mathrm{CD}_{\text {STOP }}$ and $\mathrm{CD}_{\mathrm{PER}}$ and represented the total number of capillaries visible across the distance of $1 \mathrm{~mm}$.

Intercapillary distance (ICD) was determined for each video field by averaging the video caliper measurements of the projected distances between adjacent perfused capillaries along a test line drawn perpendicular to the direction of the muscle fibers. The ICD for each of the six video fields was then averaged to determine the mean ICD for the EDL muscle. The coefficient of variation in ICD $\left(\mathrm{CV}_{\mathrm{ICD}}\right)$ was also calculated. The 75th percentile of ICD ( $\left(\mathrm{CD}_{75}\right)$ was determined for SHAM animals and was taken as an arbitrary cutoff to allow us to compare the proportion of ICD values above this value in SHAM versus CLP rats.

$V_{\mathrm{RBC}}$ was determined by means of a frame-by-frame analysis of the distance traversed by a target $R B C$ in 10 randomly chosen capillaries in each video field. The mean $V_{\mathrm{RBC}}$ for each of the six video fields was then determined, and the mean $V_{\mathrm{RBC}}$ for the EDL muscle and its coefficient of variation $\left(\mathrm{CV}_{\mathrm{VEL}}\right)$ were calculated. The 75th percentile of $V_{\mathrm{RBC}}$ $\left(V_{\mathrm{RBC} 75}\right)$ was determined for SHAM animals and was taken as an arbitrary cutoff to allow us to compare the proportion of $V_{\mathrm{RBC}}$ values above this value in SHAM versus CLP rats.

Laser Doppler flowmetry. Laser Doppler flowmetry was used as an alternate measure of microvascular perfusion. The rationale for using this technique was to obtain complimentary perfusion information from a much larger volume of tissue than just the surface sampled by intravital microscopy. Recently, we obtained an excellent agreement between these two approaches (22). We used a laser Doppler flowmeter (Periflux PF1d; Perimed, Stockholm, Sweden) to measure $Q_{\mathrm{RBC}}$ through a tissue volume of $\sim 2 \mathrm{~mm}^{3}$. $Q_{\mathrm{RBC}}$ depends on the product of $\mathrm{CD}_{\mathrm{PER}}$ and $V_{\mathrm{RBC}}$ (23). The output of this device is in arbitrary laser Doppler flow (LDF) units (volts).

The fiber optic probe from the flowmeter was placed $1 \mathrm{~mm}$ above the surface of the EDL preparation, and a stable baseline rest measurement of LDF was taken. This was repeated at two other sites, and the three values were averaged to obtain a mean $L_{D F}$ PRE that represented the muscle $Q_{\mathrm{RBC}}$ at rest. The EDL muscle was then stimulated at 4-5 $\mathrm{V}$ to contract at $6 \mathrm{~Hz}$ for $1 \mathrm{~min}$ with a pulse stimulator (S88; Grass 
Table I. The Effects of CLP

\begin{tabular}{|c|c|c|c|}
\hline Variable & SHAM & CLP & $P$ valu \\
\hline Weight $(g)$ & $369 \pm 10$ & $392 \pm 18$ & NS \\
\hline Temperature $\left({ }^{\circ} \mathrm{C}\right)$ & $38.3 \pm 0.3$ & $36.6 \pm 0.4$ & 0.009 \\
\hline Heart rate $(b p m)$ & $406 \pm 16$ & $438 \pm 19$ & NS \\
\hline Mean arterial pressure $(\mathrm{mmHg})$ & $111 \pm 3$ & $104 \pm 4$ & NS \\
\hline Central venous pressure $(\mathrm{mmHg})$ & $3 \pm 1$ & $5 \pm 1$ & NS \\
\hline Cardiac index $(\mathrm{m} / / 100 \mathrm{~g}$ per min $)$ & $48.3 \pm 4.8$ & $49.9 \pm 6.3$ & NS \\
\hline Hemoglobin $(g /$ liter $)$ & $99.1 \pm 8.8$ & $71.9 \pm 4.6$ & NS \\
\hline Polymorphonucleocyte $\left(\times 10^{6} /\right.$ liter $)$ & $3.8 \pm 1.2$ & $1.1 \pm 0.3$ & 0.031 \\
\hline Lymphocyte $\left(\times 10^{6} /\right.$ liter $)$ & $3.7 \pm 0.8$ & $1.4 \pm 0.2$ & 0.017 \\
\hline Lactate (mmolliter) & $0.9 \pm 0.2$ & $2.0 \pm 0.2$ & 0.002 \\
\hline Arterial pH & $7.46 \pm 0.01$ & $7.45 \pm 0.01$ & NS \\
\hline Arterial $\mathrm{pCO}_{2}(\mathrm{mmHg})$ & $35.5 \pm 3.0$ & $32.5 \pm 1.9$ & NS \\
\hline Arterial $\mathrm{pO}_{2}(\mathrm{mmHg})$ & $95.7 \pm 5.8$ & $99.9 \pm 3.4$ & NS \\
\hline Arterial $\mathrm{O}_{2}$ saturation $(\%)$ & $93.7 \pm 1.9$ & $93.4 \pm 1.0$ & NS \\
\hline
\end{tabular}

Instrument Co., Quincy, MA); this degree of field stimulation has been shown previously not to cause direct microcirculatory effects (24). After the cessation of this electrical twitch stimulation, the peak reactive hyperemia ( $\mathrm{LDF}_{\mathrm{POST}}$ ) was measured. The LDF was then recorded at prespecified time intervals over the next $15 \mathrm{~min}$ to determine the time course of recovery of the reactive hyperemia; after a further $30-\mathrm{min}$ recovery period, the EDL muscle was again stimulated, and the reactive hyperemia was remeasured as above. The two sets of data were averaged, and an exponential function $\left(y=\mathrm{A} \mathrm{e}^{-\mathrm{t} / \tau}+\mathrm{B}\right)$ was computer fitted (Sigmaplot v4.1; Jandel Scientific, Corte Madera, CA) to the result for determination of the time constant of decay $(\tau)$ for the recovery period. $\tau$ was a measure of how quickly the LDF returned to baseline values.

Statistics. The data are expressed as mean \pm standard error of the mean. Comparisons between groups were performed with the MannWhitney test. In the case of repeated measures, comparison between and within groups was performed with a two-way repeated measures ANOVA and appropriate post-hoc tests. In the case where baseline values were significantly different between groups, a two-way analysis of covariance (ANCOVA) was performed. Comparison of proportions was done with the $\chi^{2}$ test. All statistics were calculated using a standard computer software package (SPSS v3.1; SPSS Inc., Chicago, IL). A $P$ value of $<0.05$ was considered significant.

\section{Results}

The data from the baseline awake study in SHAM $(n=7)$ and CLP $(n=8)$ rats are presented in Table I. When compared with the SHAM rats, the CLP rats showed a significant decrease of $4.3 \%$ in TEMP, a $70 \%$ decrease in polymorphonucleocyte count, a $61 \%$ decrease in lymphocyte count, and a $114 \%$ increase in arterial LACT. There were no significant differences between groups in MAP, cardiac index $(\mathrm{CI})$, arterial $\mathrm{pH}$, and $\mathrm{pCO}_{2}$.

With the induction of general anesthesia, there was a significant decrease in MAP (Fig. 1) in both the SHAM and CLP groups (ANOVA, $P=0.001$ ); however, a group-specific interaction with the anesthetic was not found as the MAP for both groups of rats decreased to the same extent and remained above $100 \mathrm{mmHg}$. Anesthesia did not significantly alter the CI or LACT. All the MAP, CI, and LACT subsequently remained unchanged in both the SHAM and CLP groups throughout the remainder of the 4-h study period.

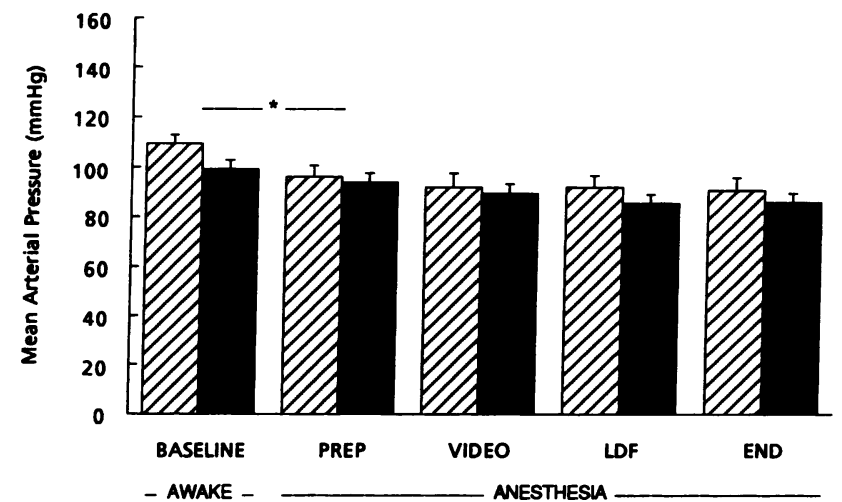

Figure 1. The effect of anesthesia on the MAP in SHAM and CLP rats. Anesthesia did significantly lower MAP but there was no difference in its effect between SHAM or CLP rats. MAP subsequently remained stable throughout the period of anesthesia in both groups. ${ }^{*} P=0.007$.

Intravital videomicroscopy. CLP rats had a $265 \%$ increase in $\mathrm{CD}_{\text {STOP }}$ (from $0.9 \pm 0.2$ to $3.3 \pm 0.4$ capillaries $/ \mathrm{mm}$ of test line) and a 39,36 , and $29 \%$ decrease in $\mathrm{CD}_{\text {CONT }}$ (from $31.04 \pm 1.36$ to $19.26 \pm 1.07$ capillaries $/ \mathrm{mm}$ ), $\mathrm{CD}_{\mathrm{PER}}$ (from $35.3 \pm 1.5$ to $22.5 \pm 1.0$ capillaries $/ \mathrm{mm}$ ), and $\mathrm{CD}_{\text {TOT }}$ (from $36.5 \pm 1.6$ to $25.9 \pm 0.8$ capillaries $/ \mathrm{mm}$ ), respectively, while $\mathrm{CD}_{\text {INTER }}$ remained unchanged when compared with the SHAM rats (Fig. 2 ). Fig. 3 shows the frequency distribution of $C D_{P E R}$ for $S H A M$ and CLP groups; not only were the means of the two groups different but the CV for the CLP group was $72 \%$ greater than the SHAM group. Qualitatively, precapillary arterioles and postcapillary venules in CLP rats appeared to be perfused as in SHAM rats.

The mean ICD was $30 \%$ larger in the CLP rats than in the SHAM rats $(33.5 \pm 1.6$ vs $25.7 \pm 0.9 \mu \mathrm{m} ; P=0.001)$, while the CV was $27 \%$ larger in the CLP rats (Fig. 4). There was also a significantly greater proportion of capillary pairs with an ICD $>33.8 \mu \mathrm{m}$ (the $\mathrm{ICD}_{75}$ in SHAM rats) in the CLP rats $(39.2 \%$; $\left.\chi^{2}, P=0.0001\right)$.

The mean $V_{\mathrm{RBC}}(319 \pm 41$ vs $325 \pm 30 \mu \mathrm{m} / \mathrm{s} ; P=\mathrm{NS})$ and the CV (200 \pm 39 vs $300 \pm 51 \% ; P=N S)$ were not different between the SHAM and CLP groups when velocities from all capillary types were included. However, when only perfused capillaries were analyzed, (Fig. 5) the mean $V_{\mathrm{RBC}}$ was increased in the CLP group compared with the SHAM group (391 16

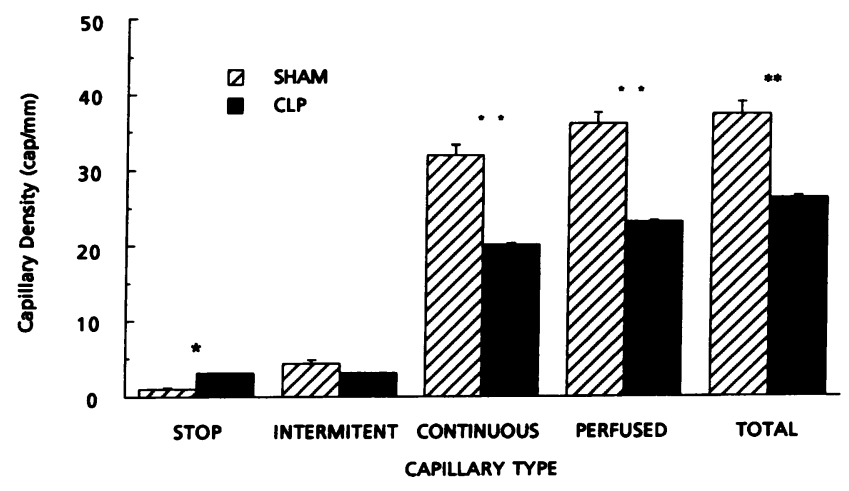

Figure 2. Densities of the various capillary types. Stopped-flow capillary density increased while continuous flow, perfused, and total capillary density decreased. $* P<0.01 ; * * P<0.001$. 


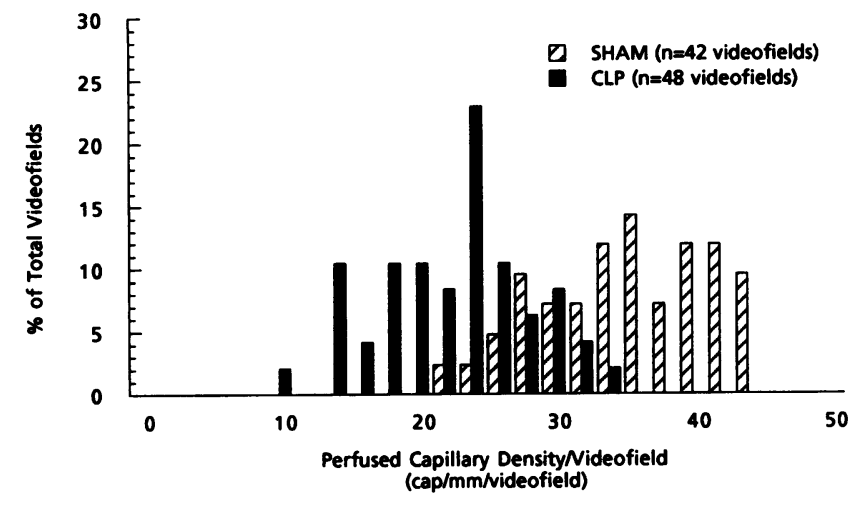

Figure 3. Distribution of perfused capillary densities for SHAM and CLP rats. Note the left shift of the CLP curve to lower densities. The coefficient of variation for the CLP rats was greater than the SHAM rats $(22.6 \pm 2.6$ vs $14.1 \pm 1.2 \%, P<0.021)$. Each individual rat had a distribution similar to the mean distribution of their respective group; these distributions were not due to inter-animal variations.

vs $333 \pm 15 \mu \mathrm{m} / \mathrm{s} ; P=0.0002)$, and the CV (94.7 \pm 6.6 vs $77.8 \pm 4.8 \% ; P=\mathrm{NS}$ ) was not statistically different. The CLP group had a greater proportion of capillaries with either $0 \mu \mathrm{m} /$ s velocity ( 16.9 vs $4.0 \% ; \chi^{2}, P=0.05$ ) or $>401 \mu \mathrm{m} / \mathrm{s}$ (the $V_{\mathrm{RBC75}}$ in SHAM rats) velocity $\left(29.2 \% ; \chi^{2}, P=0.0537\right)$.

Laser Doppler flowmetry. During the baseline rest study, the laser Doppler flow ( $\mathrm{LDF}_{\mathrm{PRE}}$ ) was $36 \%$ lower in the CLP rats (Fig. 6). After muscle stimulation, $\mathrm{LDF}_{\mathrm{POST}}$ was significantly increased in both the SHAM and CLP groups but the relative increase in the CLP group was less than in the SHAM group when the difference in baseline LDF was taken into account (ANCOVA, $P=0.006)$. The time constant of LDF decay $(\tau)$ for the recovery phase was $191 \pm 38 \mathrm{~s}^{-1}$ in the CLP group and $148 \pm 25 \mathrm{~s}^{-1}$ in the SHAM group $(P=0.355)$.

\section{Discussion}

Sepsis is associated with abnormalities in tissue oxygen utilization that could arise from inappropriate distribution of oxygen at the microregional level. This in turn may lead to tissue injury

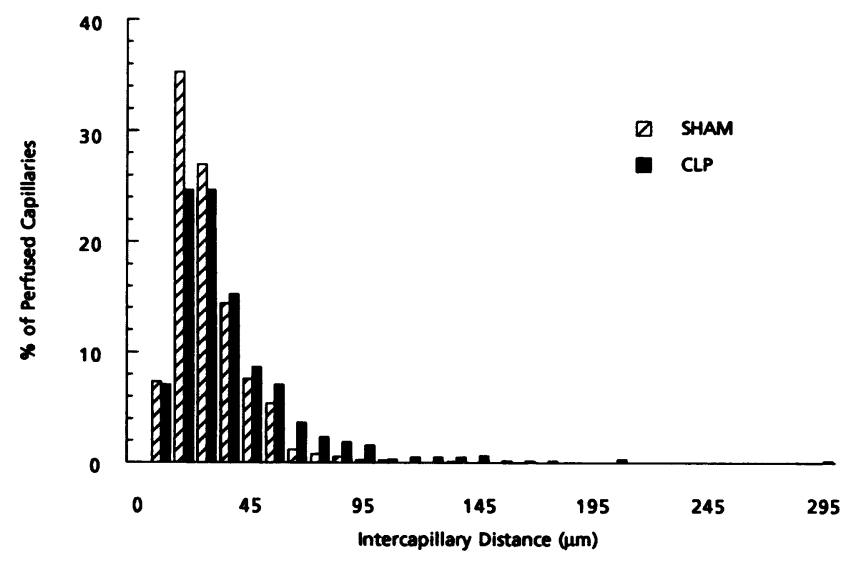

Figure 4. Frequency distribution of ICD for SHAM and CLP rats. The curve for the CLP rats is right shifted to wider spaced capillary pairs. The coefficient of variation in ICD for the CLP rats was greater than in the SHAM rats $(73.1 \pm 6.0$ vs $57.8 \pm 1.4 \%, P<0.038)$.

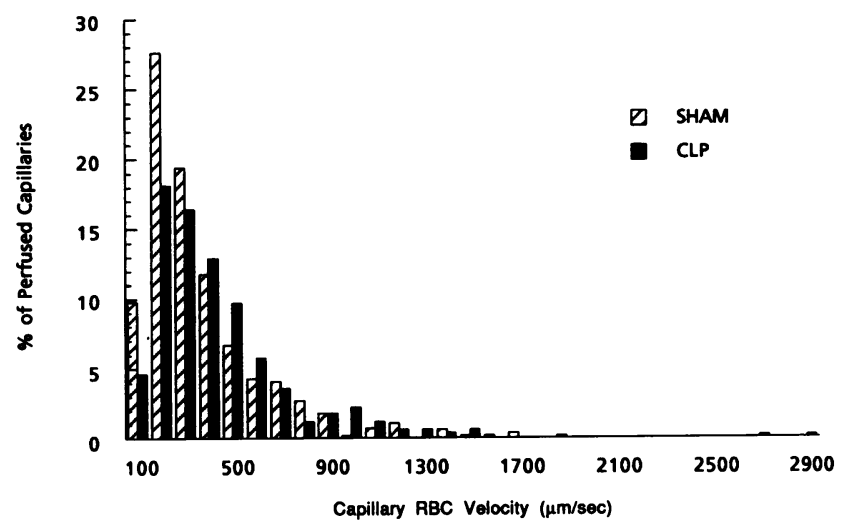

Figure 5. Frequency distribution for capillary $\mathrm{RBC}$ velocity $\left(V_{\mathrm{RBC}}\right)$ in SHAM and CLP rats. The curve for the CLP rats is right shifted to higher velocities. The coefficient of variation in $V_{\mathrm{RBC}}$ for the CLP rats was not different from the SHAM rats $(94.7 \pm 6.6$ vs $77.8 \pm 4.8 \%)$.

and may underlie the development of MODS. We hypothesized that sepsis alters the ability of the host's microcirculation to appropriately control $Q_{\mathrm{RBC}}$ within the parenchyma of organs distant from the site of infection. In a model of normotensive sepsis as a complication of peritonitis, we found that this syndrome was associated with significant changes in microvascular perfusion manifesting as: (a) a decrease in the density of RBCperfused capillaries; $(b)$ an increase in the spatial heterogeneity of RBC-perfused capillaries; $(c)$ an increase in the proportion of widely spaced RBC-perfused capillaries; $(d)$ an increase in capillary mean $\mathrm{RBC}$ velocity; and $(e)$ a decrease in peak functional hyperemic response. These changes confirm the existence of a defect in the ability of the skeletal muscle to regulate its $Q_{\mathrm{RBC}}$ and may lead to the development of microregional areas of hypoxia and cell injury.

The model. We used a model that was developed and extensively characterized in our laboratory (19). Rats in the CLP group exhibited changes over time that were consistent with the development of sepsis. They were hypothermic, leukopenic, and had elevated arterial lactates when compared with the SHAM rats. Of particular note, the CLP rats remained normotensive and were not hypodynamic. Therefore, this model meets criteria consistent with the diagnosis of chronic, resuscitated sepsis (6, 25 ). It is unlike models of septic shock in which hypotension or decreased cardiac output may confound the interpretation of events in the microcirculation (26). Our model also permits time for evolution of the septic response (27), a feature lacking from previous studies that reported the acute effects of a bolus or infusion of endotoxin or bacteria. As well, none of our rats were artificially ventilated and all had normal arterial $\mathrm{pH}, \mathrm{pCO}_{2}$ and $\mathrm{pO}_{2}$, other factors that are also known to affect the functioning of the microcirculation in skeletal muscle.

Although anesthetics are also known to affect the circulatory system, the use of such an agent during the study was unavoidable. The only significant effect found after anesthesia was a minor decrease in blood pressure; however, the rats remained normotensive, and the changes were similar in both the SHAM and CLP groups. In an earlier study, we did not find any significant effect of this anesthetic regimen on blood flow to the gastrocnemius muscle (28). We do not, therefore, consider the use of our anesthetic regimen a contributing factor to the results obtained.

We chose to use skeletal muscle in this initial study since 


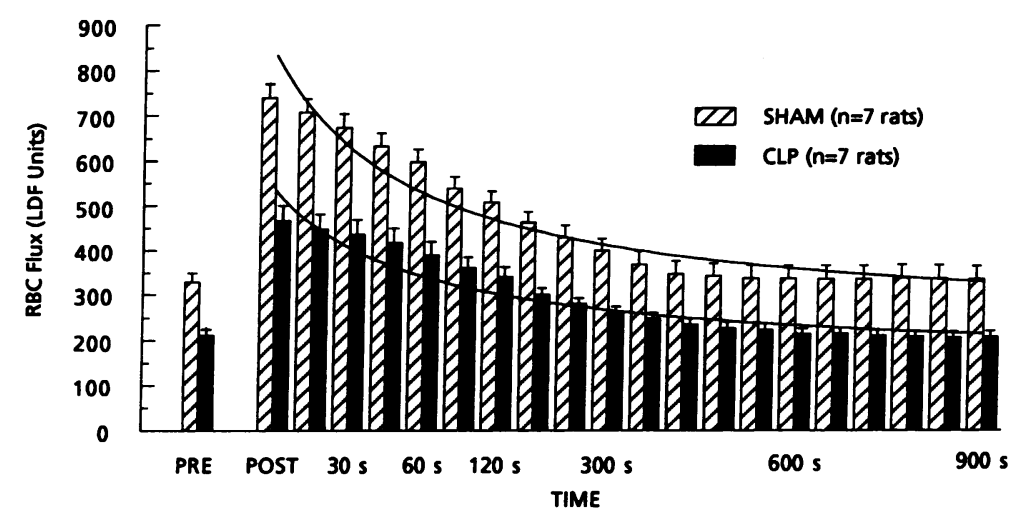

Figure 6. RBC flux before and during the recovery phase after electrical field stimulation of the EDL muscle in SHAM and CLP rats. The RBC flux was significantly lower in the CLP rats at the PRE time period $(P=0.001)$. It increased significantly in both the SHAM and CLP rats after twitch stimulation $(P<0.001)$, however, the SHAM rats had a relatively greater increase (ANCOVA, $P$ $=0.006)$. The lines were computer fitted. it was the best characterized tissue in our laboratory and in the literature. We recognized that the behavior of the microvasculature in this tissue may not be representative of the microcirculation of other tissues, however, we have subsequently found similar changes with sepsis in the microcirculation of the small bowel mucosa (29).

Intravital videomicroscopy. We found that sepsis was associated with a significant decrease in the density of RBC perfused capillaries $\left(\mathrm{CD}_{\mathrm{PER}}\right)$. Our finding agrees with a recent report from Boczkowski and co-workers (30) who also employed intravital microscopy to study microcirculatory responses in a rat model of sepsis. They found a decrease in the percentage of perfused capillaries in the diaphragm of endotoxin-treated rats. However, they did not address any sepsis effects on the heterogeneity of capillary blood flow. As well, Barroso-Aranda and co-workers (31) showed a decrease in the number of carbonperfused capillaries in histological samples of myocardium from an acute endotoxin-shock rat model of sepsis. Finally, a morphologic study by Drazenovic and co-workers (17) demonstrated a decrease in the number of functional capillaries in gut mucosa of anesthetized, endotoxin-shocked dogs. Although these latter three studies were unable to differentiate the individual effect of sepsis on the microcirculation from that of hypotension, our study suggests that abnormalities in the microcirculation can arise independent of the presence of shock.

Although in part due to an increase in the density of stoppedflow capillaries $\left(\mathrm{CD}_{\mathrm{STOP}}\right)$, this decrease in $\mathrm{CD}_{\mathrm{PER}}$ was primarily due to a decrease in the density of total capillaries $\left(\mathrm{CD}_{\mathrm{TOT}}\right)$. The mechanisms underlying these findings are unclear. Although an increase in $\mathrm{CD}_{\text {sTop }}$ has been reported previously in a model of ischemia-reperfusion, a decrease in the total number of capillaries was not a feature of this model (32). There are a number of potential mechanisms in sepsis that may contribute (most likely in combination) to the increase in $\mathrm{CD}_{\text {sTop }}$ we observed, including: (a) capillary endothelial cell injury and swelling resulting in a decrease in luminal cross-sectional area (33) and increase in resistance to flow; $(b)$ reduced $\mathrm{RBC}$ fluidity resulting in an increase in blood viscosity $(12,34) ;(c)$ leukocyte plugging of capillaries (31); and (d) leukocyte adhesion in postcapillary venules $(35,36)$ resulting in an increase in capillary outflow resistance and reduced $\mathrm{RBC}$ shear rate, which are important determinants of capillary RBC flow (37).

The decrease in $C D_{\text {тот }}$ that we observed was likely due to an increase in nonperfused (plasma and cells) capillaries and/ or plasma-only perfused capillaries. These capillary sub-types would not have been found by our method since it relies on the identification of RBCs for the detection of capillaries. Nonethe- less, neither of these capillary subtypes would be carrying RBCs and, therefore, would contribute negligibly to oxygen delivery in the muscle. These nonperfused capillaries most likely developed as a result of the same mechanisms as discussed above for the stopped-flow capillaries. It was also possible that the decrease in $\mathrm{CD}_{\text {Tот }}$ was secondary to an increase in true intercapillary distance due to the presence of interstitial edema. However, our recent study in skeletal muscle provided evidence against edema as the cause (38).

Despite the changes in arteriolar diameter and reactivity shown by Cryer and co-workers $(10,11)$, it is important to note that our observed loss of functional capillaries appeared to involve individual capillaries. Thus, random individual capillaries seemed to be affected as opposed to a bed of capillaries related to a single arteriole or venule. The aforementioned study by Barroso-Aranda and co-workers (31) also showed a lack of obstruction in the arterioles and venules. This loss of functional capillaries appeared to be an all-or-none phenomenon. We failed to find a difference in the density of intermittently perfused capillaries $\left(C D_{\text {INTER }}\right)$, whereas an increase would have been expected if the injury was on a continuum. This is in contrast to a study by Dawson and co-workers (32) in a skeletal muscle model of ischemia-reperfusion that showed that the number of intermittently perfused capillaries increased after injury. This discrepancy could be explained by the differences in the time point at which the animals were studied. They studied their animals $7 \mathrm{~d}$ after a defined period of injury, while our rats were studied after $1 \mathrm{~d}$ of an evolving injury. We may have allowed less time for recovery of capillary RBC perfusion.

Not only was $\mathrm{CD}_{\mathrm{PER}}$ decreased, but the distribution of the remaining RBC-perfused capillaries was also affected by sepsis. This was reflected by an increase in the coefficient of variation of $\mathrm{CD}_{\mathrm{PER}}\left(\mathrm{CV}_{\mathrm{CD}}\right)$ which represents an increase in the spatial heterogeneity of $\mathrm{CD}_{\mathrm{PER}}$. In other words, there was increased variability in mean capillary density between fields in CLP rats while all fields were similar in SHAM rats. Spatial heterogeneity of microvascular flow is thought to be an important physiological parameter determining the efficiency of exchange of materials between blood and tissue (39). (This increased heterogeneity in $\mathrm{CD}_{\mathrm{PER}}$ provided further evidence against edema as the major contributing factor to the decrease in $\mathrm{CD}_{\text {TOT }}$. Edema would result in a more uniform, rather than heterogenous, change in $\mathrm{CD}_{\mathrm{PER}}$.)

The corollary to a decrease in capillary density is, of course, an increase in ICD. Therefore, it was not surprising that we found an increase in mean ICD and an increase in the $C_{\text {ICD }}$ with sepsis. Were the greatest ICDs wide enough to increase 
oxygen diffusion distances to the point where tissue hypoxia would result? Observations made in malignant tumors have shown that intercapillary distances $>76-134 \mu \mathrm{m}$ would be required before cellular hypoxia would arise (40). This value was derived from three dimensional histologic cross-sections of tissues and cannot be applied to our data directly since we were looking at two dimensional surface projections of the capillary networks which would make apparent distances smaller. Nevertheless, from the data for Fig. 4, we estimated that in the SHAM rats only $1.2-0 \%$ of the ICDs were greater than the above quoted values, respectively, while in the CLP rats 6.8$1.6 \%$ were greater. Therefore, there were microregions in the septic rats with ICDs wide enough to result in a greater likelihood of developing hypoxia.

$V_{\mathrm{RBC}}$ is another variable that contributes to the efficiency of oxygen delivery to the tissues. Although it is dependent on multiple factors, optimal oxygen off-loading in skeletal muscle is achieved within a narrow range of $V_{\mathrm{RBC}}(41)$. In the present study, the mean $V_{\mathrm{RBC}}$ of the EDL muscle was no different in the CLP rats when compared with the SHAM rats, but this was primarily due to an increase in the number of stopped-flow ( 0 $\mu \mathrm{m} / \mathrm{s}$ ) capillaries. This lack of change in $V_{\mathrm{RBC}}$ was consistent with the reported lack of change in blood flow in skeletal muscle with sepsis (42). However, when only RBC-perfused capillaries were analyzed, sepsis was associated with an increase in the mean $V_{\mathrm{RBC}}$. This change could be compensatory since it would increase the bulk oxygen delivery per unit of time; however, excessively high $V_{\mathrm{RBC}}$ could also result in microregional areas of hypoxia secondary to nonoptimal oxygen off-loading times.

It has been estimated that the lower bound for the residence or transit time of an RBC through a capillary should be no less than $0.04 \mathrm{~s}$ (43). This is the minimum time required for the $\mathrm{RBC}$ oxygen saturation to fall from 80 to $30 \%$ if the tissue oxygen saturation were $0 \%$. The actual transit time needed to unload this much oxygen would be significantly longer in vivo since tissue oxygen saturation levels are higher than $0 \%$. We could not measure the RBC transit times in our study since our methodology did not allow us to see complete arteriovenous units. However, some video fields did contain complete capillary beds. From these, we estimated that the mean arteriovenous length was $415 \pm 20 \mu \mathrm{m}$ in the SHAM rats and $444 \pm 16 \mu \mathrm{m}$ in the CLP rats (difference not significant). These values are in agreement with values reported in other rat muscles (44). Using these average lengths and the average velocity in the upper quartile of each group, the average transit time of the fastest traveling RBCs was estimated as $0.6 \mathrm{~s}$ in the SHAM rats and $0.5 \mathrm{~s}$ in the CLP rats. Both of these values are well above the minimum value; however, a small percentage of $V_{\mathrm{RBC}} \mathrm{S}$ in the CLP group had exceptionally high values $(>2,500 \mu \mathrm{m} / \mathrm{s})$ which yields transit times on the order of $0.15 \mathrm{~s}$. These values could potentially be critical in the animal.

Could some of these "high velocity" capillaries be acting as "peripheral shunts"? It has been postulated that some of the peripheral inefficiency in oxygen use in sepsis may be due to the presence of tissue arteriovenous shunts, but these have never been proven. In our study, the presence of higher RBC velocities may contribute to the decreased oxygen extraction and increased mixed venous oxygen saturation seen with sepsis, but it appears that the maldistribution of RBC flux shown by our data may be more important.

Laser Doppler flowmetry. At rest, $\mathrm{LDF}_{\mathrm{PRE}}$ was significantly lower in the CLP group when compared with the SHAM group, suggesting impairment of $Q_{\mathrm{RBC}}$ by sepsis. This was consistent with the finding of decreased perfused capillary density from the intravital videomicroscopy portion of the study. Other models of sepsis have often used radioactive microspheres for the measurement of blood flow to the skeletal muscle of the hind limb and have variably shown flow to decrease (45) or not change (46) with sepsis. These differences may have been due to differences in technique such as whether the animals were anesthetized or awake. The awake state could affect the amount of muscle activity and, therefore, blood flow.

After electrical field-stimulated contraction of the EDL muscle, LDF increased in both the CLP and SHAM groups, however, the peak hyperemia $\left(\mathrm{LDF}_{\mathrm{POST}}\right)$ was significantly lower in the CLP group. This was not due to a low resting blood flow but to a truly depressed response in sepsis. There was also a trend for the time constant of decay $(\tau)$, a measure of how quickly the LDF returns to resting levels, to be increased with CLP, although it did not reach statistical significance due to a lack of statistical power. This would suggest an impaired ability of the EDL microcirculation to recover from the applied stress. These findings are consistent with studies in humans that have used impedance plethysmography to measure reactive hyperemia after a transient period of forearm ischemia $(47,48)$.

The significance of the depression in the functional hyperemic response seen in the CLP rats is unclear. It could represent an impaired ability of the microvasculature to respond to a local increase in oxygen demand through a failure to increase perfused capillary density or reduce flow heterogeneity. In addition, Cryer and Garrison (49) have shown that first to fourth order arterioles have altered vascular reactivity in an endotoxemia model of sepsis. This combination of defects may impair the ability to increase oxygen delivery to the tissues in response to an increase in demand. This may predispose the tissue to the development of hypoxia, particularly in the presence of the pathologic oxygen supply dependency associated with sepsis $(2,5)$.

The heterogeneous distribution of capillary RBC flux and the increase in the proportion of large intercapillary distances that we have observed could be responsible for an inappropriate distribution of oxygen within the EDL muscle in sepsis. This in turn may lead to microregional areas of hypoxia which may potentially be the underlying cause of the parenchymal cell injury seen in MODS. From the current study, however, we were unable to determine whether these observed alterations actually produced cellular injury.

In summary, sepsis impairs skeletal muscle microvascular perfusion by decreasing the density of perfused capillaries, increasing the spatial heterogeneity of perfused capillaries, increasing the proportion of widely spaced capillaries, increasing RBC velocity, and by impairing its reactive hyperemic response. We speculate that these changes may lead to the development of microregional areas of hypoxia, which in turn may cause parenchymal cell injury. This may be an underlying mechanism for the development of multiple organ dysfunction.

\section{Acknowledgments}

The authors wish to gratefully acknowledge the technical assistance of Hua Xiong.

This study was supported by grants from the Medical Research Council of Canada (to C. Lam and K. Tyml), the Ontario Thoracic Society (to C. Martin), and the Ontario Heart and Stroke Foundation (to W. Sibbald). 


\section{References}

1. Bredle, D. L., R. W. Samsel, P. T. Schumacker, and S. M. Cain. 1989. Critical $\mathrm{O}_{2}$ delivery to skeletal muscle at high and low $\mathrm{PO}_{2}$ in endotoxemic dogs. J. Appl. Physiol. 66:2553-2558.

2. Nelson, D. P., R. W. Samsel, L. D. Wood, and P. T. Schumacker. 1988. Pathological supply dependence of systemic and intestinal $\mathrm{O}_{2}$ uptake during endotoxemia. J. Appl. Physiol. 64:2410419.

3. Tuchschmidt, J., D. Oblitas, and J. C. Fried. 1991. Oxygen consumption in sepsis and septic shock. Crit. Care Med. 19:664-671.

4. Dahn, M. S., R. F. Wilson, P. Lange, A. Stone, and L. A. Jacobs. 1990. Hepatic parenchymal oxygen tension following injury and sepsis. Arch. Surg. 125:441-443.

5. Tuchschmidt, J., J. Fried, M. Astiz, and E. Rackow. 1992. Elevation of cardiac output and oxygen delivery improves outcome in septic shock. Chest. 102:216-220.

6. Bone, R. C. 1991. Gram-negative sepsis. Background, clinical features, and intervention. Chest. 100:802-808.

7. Hersch, M., A. A. Gnidec, A. D. Bersten, M. Troster, F. S. Rutledge, and W. J. Sibbald. 1990. Histologic and ultrastructural changes in nonpulmonary organs during early hyperdynamic sepsis. Surgery (St. Louis). 107:397-410.

8. Stahl, T. J., P. B. Alden, W. S. Ring, R. C. Madoff, and F. B. Cerra. 1990. Sepsis-induced diastolic dysfunction in chronic canine peritonitis. Am. J. Physiol. 258:H625-H633.

9. Schumacker, P. T., and R. W. Samsel. 1989. Oxygen delivery and uptake by peripheral tissues: physiology and pathophysiology. Crit. Care Clin. 5:255269.

10. Cryer, H. M., R. N. Garrison, H. W. Kaebnick, P. D. Harris, and L. M Flint. 1987. Skeletal microcirculatory responses to hyperdynamic Escherichia col sepsis in unanesthetized rats. Arch. Surg. 122:86-92.

11. Cryer, H. M., R. N. Garrison, and P. D. Harris. 1988. Role of muscle microvasculature during hyperdynamic and hypodynamic phases of endotoxin shock in decerebrate rats. J. Trauma. 28:312-318.

12. Baker, C. H., and D. L. Davis. 1980. Endotoxin effects on capillary transit times of RBC and plasma as measured by indicator dilution. Microvasc. Res. 20:242-252.

13. Baker, C. H., F. R. Wilmoth, and E. T. Sutton. 1986. Reduced RBC versus plasma microvascular flow due to endotoxin. Circ. Shock. 20:127-139.

14. Baker, C. H., and F. R. Wilmoth. 1984. Microvascular responses to $E$. coli endotoxin with altered adrenergic activity. Circ. Shock. 12:165-176.

15. Baker, C. H., E. T. Sutton, Z. Zhou, and D. G. Reynolds. 1990. Reduced microvascular adrenergic receptor activity due to opioids in endotoxin shock. Circ. Shock. 32:101-112.

16. Lübbe, A. S., R. N. Garrison, H. M. Cryer, N. L. Alsip, and P. D. Harris 1992. EDRF as a possible mediator of sepsis-induced arteriolar dilation in skeletal muscle. Am. J. Physiol. 262:H880-H887.

17. Drazenovic, R., R. W. Samsel, M. E. Wylam, C. M. Doerschuk, and P. T. Schumacker. 1992. Regulation of perfused capillary density in canine intestinal mucosa during endotoxemia. J. Appl. Physiol. 72:259-265.

18. Baker, C. H., and E. T. Sutton. 1991. Role of cremaster muscle arteriolar endothelium during endotoxin shock. The Fifth World Congress for Microcirculation. Louisville, Kentucky. The Microcirculatory Society, Inc. 22 (Abstract).

19. Martin, C. M., A. Yaghi, W. J. Sibbald, D. McCormack, and N. A. M. Paterson. 1993. Differential impairment of vascular reactivity of small pulmonary and systemic arteries in hyperdynamic sepsis. Am. Rev. Respir. Dis. 148:164172.

20. Martin, C. M., F. N. MacKinnon, C. Lam, and W. J. Sibbald. 1991. Minimum alveolar concentration $\left(\mathrm{MAC}_{100}\right)$ and hemodynamic effects of isoflurane in septic rats. Clin. Invest. Med. 14:24a. (Abstr.)

21. Tyml, K., and C. H. Budreau. 1991. A new preparation of rat extensor digitorum longus muscle for intravital investigation of the microcirculation. Int. J. Microcirc. Clin. Exp. 10:335-343.

22. Tyml, K., O. Mathieu-Costello, and C. H. Budreau. 1992. Distribution of red blood cell velocity in capillary network, and endothelial ultrastructure, in aged rat skeletal muscle. Microvasc. Res. 44:1-13.

23. Tyml, K., and C. G. Ellis. 1985. Simultaneous assessment of red cell perfusion in skeletal muscle by laser Doppler flowmetry and video microscopy. Int. J. Microcirc. Clin. Exp. 4:397-406.

24. Tyml, K. 1987. Red cell perfusion in skeletal muscle at rest and after mild and severe contractions. Am. J. Physiol. 252:H485-H493.

25. Bone, R. C., R. A. Balk, F. B. Cerra, R. P. Dellinger, A. M. Fein, W. A. Knaus, R. M. Schein, and W. J. Sibbald. 1992. Definitions for sepsis and organ failure and guidelines for the use of innovative therapies in sepsis. The ACCP/ SCCM Consensus Conference Committee. American College of Chest Physicians/Society of Critical Care Medicine. Chest 101:1644-1655.

26. D'Orio, V., P. Mendes, P. Carlier, M. Fatemi, and R. Marcelle. 1991. Lung fluid dynamics and supply dependency of oxygen uptake during experimental endotoxic shock and volume resuscitation. Crit. Care Med. 19:955-962.

27. Fink, M. P., and S. O. Heard. 1990. Laboratory models of sepsis and septic shock. J. Surg. Res. 49:186-196.

28. Martin, C. M., D. Cunningham, and W. J. Sibbald. 1992. Effect of isoflurane on hemodynamics and organ blood flow in a rat model of normotensive sepsis. Clin. Invest. Med. 15:143a. (Abstr.)

29. Farquhar, I., C. Lam, C. Martin, and W. Sibbald. 1993. Sepsis may decrease capillary density in the mucosa of the small bowel. Am. Rev. Respir. Dis. 147:100a (Abstr.)

30. Boczkowski, J., E. Vicaut, and M. Aubier. 1992. In vivo effects of Escherichia coli endotoxemia on diaphragmatic microcirculation in rats. J. Appl. Physiol. 72:2219-2224.

31. Barroso-Aranda, J., S. G. Schmid, B. W. Zweifach, and J. C. Mathison. 1991. Polymorphonuclear neutrophil contribution to induced tolerance to bacterial lipopolysaccharide. Circ. Res. 69:1196-1206.

32. Dawson, J. M., B. I. Okyayuz, and O. Hudlicka. 1990. Skeletal muscle microcirculation: the effects of limited blood supply and treatment with torbafylline. Int. J. Microcirc. Clin. Exp. 9:385-400.

33. Morisaki, H., F. Bloos, A. Neal, M. Pitt, L. Cross, J. Keys, C. M. Martin, and W. J. Sibbald. 1992. Colloid infusion preserves microvascular integrity better than crystalloid in hyperdynamic sepsis. Crit. Care Med. 20(Suppl. 1): S101a. (Abstr.)

34. Puranapanda, V., L. B. Hinshaw, E. A. O'Rear, A. C. Chang, and T. L. Whitsett. 1987. Erythrocyte deformability in canine septic shock and the efficacy of pentoxifylline and a leukotriene antagonist. Proc. Soc. Exp. Biol. Med. $185: 206-210$

35. Svensjö, E., M. Erlansson, and G. van den Bos. 1990. Endotoxin-induced increase in leukocyte adherence and macromolecular permeability of postcapillary venules. Agents Actions. 29:21-23.

36. Matsuda, T., I. Rubinstein, R. A. Robbins, S. Koyama, W. L. Joyner, and S. I. Rennard. 1991. Role of neutrophils in endotoxin-mediated microvascular injury in hamsters. J. Appl. Physiol. 71:307-313.

37. Gaehtgens, P. 1988. Microvascular flow disturbances: rheologic aspects. In Microcirculation in Circulatory Disorders. Vol. 2. H. M. Zweifach and B. W. Messmer, editors. Springer-Verlag New York Inc., New York. 391

38. Flamand, F. J., W. J. Sibbald, M. J. Girotti, and C. M. Martin. 1994. Pentoxifylline does not prevent microvascular injury in normotensive, septic rats. Crit. Care Med. In press.

39. Tyml, K. 1991. Heterogeneity of microvascular flow in rat skeletal muscle is reduced by contraction and by hemodilution. Int. J. Microcirc. Clin. Exp. $10: 75-86$.

40. Olive, P. L., C. Vikse, and M. J. Trotter. 1992. Measurement of oxygen diffusion distance in tumor cubes using a fluorescent hypoxia probe. Int. J. Radiat. Oncol. Biol. Phys. 22:397-402.

41. Gutierrez, G. 1986. The rate of oxygen release and its effect on capillary $\mathrm{O}_{2}$ tension: a mathematical analysis. Respir. Physiol. 63:79-96.

42. Martin, C. M., and W. J. Sibbald. 1994. Modulation of hemodynamics and organ blood flow by nitric oxide synthase inhibition is not altered in normotensive, septic rats. Am. Rev. Respir. Dis. In press.

43. Popel, A. S. 1989. Theory of oxygen transport to tissue. Crit. Rev. Biomed. Eng. 17:257-321.

44. Potter, R. F., S. Houghton, and A. C. Groom. 1989. Oxygen transport to tissue XI. In Capillary Lengths and Anastomses in Rat Hindlimb Muscles, Studied by Aquablak Perfusion During Rest Versus Exercise. K. Rakusan and G. P. Biro, editors. Plenum Publishing Corp., Toronto.

45. Bersten, A. D., A. A. Gnidec, F. S. Rutledge, and W. J. Sibbald. 1990 Hyperdynamic sepsis modifies a PEEP-mediated redistribution in organ blood flows. Am. Rev. Respir. Dis. 141:1198-1208.

46. Martin, C. M., L. Cross, and W. J. Sibbald. 1992. Modulation of organ blood flow by endothelium-derived relaxant factor is not altered in sepsis. Am. Rev. Respir. Dis. 145:312a. (Abstr.)

47. MacKinnon, F. N., W. J. Sibbald, M. J. Arnold, and C. M. Martin. 1992 Dopexamine hydrochloride increases oxygen delivery and reactive hyperemia in moderately ill septic patients. Crit. Care Med. 20 (Suppl. 1): S101a. (Abstr).

48. Astiz, M. E., E. Tilly, E. D. Rackow, and M. H. Weil. 1991. Peripheral vascular tone in sepsis. Chest. 99:1072-1075.

49. Garrison, R. N., and H. M. Cryer. 1989. Role of the microcirculation to skeletal muscle during shock. Prog. Clin. Biol. Res. 299:43-52. 